\title{
Rhamnolipids and surfactin inhibit the growth or formation of oral bacterial biofilm
}

\author{
Ryota Yamasaki* ${ }^{*}$, Aki Kawano, Yoshie Yoshioka and Wataru Ariyoshi
}

\begin{abstract}
Background: Bacteria survive in various environments by forming biofilms. Bacterial biofilms often cause significant problems to medical instruments and industrial processes. Techniques to inhibit biofilm formation are essential and have wide applications. In this study, we evaluated the ability of two types of biosurfactants (rhamnolipids and surfactin) to inhibit growth and biofilm formation ability of oral pathogenic bacteria such as Aggregatibacter actinomycetemcomitans, Streptococcus mutans, and Streptococcus sanguinis.

Results: Rhamnolipids inhibited the growth and biofilm formation ability of all examined oral bacteria. Surfactin showed effective inhibition against $S$. sanguinis ATCC10556, but lower effects toward A. actinomycetemcomitans Y4 and S. mutans UA159. To corroborate these results, biofilms were observed by scanning electron microscopy (SEM) and confocal microscopy. The observations were largely in concordance with the biofilm assay results. We also attempted to determine the step in the biofilm formation process that was inhibited by biosurfactants. The results clearly demonstrated that rhamnolipids inhibit biofilm formation after the initiation process, however, they do not affect attachment or maturation.
\end{abstract}

Conclusions: Rhamnolipids inhibit oral bacterial growth and biofilm formation by A. actinomycetemcomitans Y4, and may serve as novel oral drug against localized invasive periodontitis.

Keywords: Biofilm inhibition, Oral bacteria, Rhamnolipids, Surfactin

\section{Background}

Biofilms are three-dimensional structures consisting of various microbial populations attached to a surface by extracellular polymeric substances (EPS) produced by these microorganisms [1]. Bacteria are physically shielded from external stresses by this extracellular matrix, [2]. Although biofilms can be beneficial in industrial processes such as wastewater treatment [3], fermentation [4], and microbial fuel cells $[5,6]$, they can also cause harmful effects, including biocorrosion by sulfate-reducing bacteria [7], infection due to biofilm formation on medical devices,

\footnotetext{
* Correspondence: r18yamasaki@fa.kyu-dent.ac.jp

Division of Infections and Molecular Biology, Department of Health

Promotion, Kyushu Dental University, Kitakyushu, Fukuoka 803-8580, Japan
}

such as catheters, pacemakers, and artificial joints [8], and oral diseases such as tooth decay and periodontal disease [9]. Streptococcus mutans, a representative bacteria of tooth decay [10], forms plaques (biofilm) on tooth surfaces and produces lactate from sugars such as sucrose, which demineralizes teeth and causes dental caries. Streptococcus sanguinis is another plaque-forming strain that has been reported to cause infective endocarditis by forming biofilms on the endocardium and heart valves [11]. Aggregatibacter actinomycetemcomitans has been strongly associated with localized aggressive periodontitis via its ability to form biofilms in the subgingival cavity [12] Apart from causing oral diseases, these pathogenic bacteria also cause systemic diseases, such as arteriosclerosis [13] and diabetes [14]. Therefore, removal of

(c) The Author(s). 2020 Open Access This article is licensed under a Creative Commons Attribution 4.0 International License, which permits use, sharing, adaptation, distribution and reproduction in any medium or format, as long as you give appropriate credit to the original author(s) and the source, provide a link to the Creative Commons licence, and indicate if changes were made. The images or other third party material in this article are included in the article's Creative Commons licence, unless indicated otherwise in a credit line to the material. If material is not included in the article's Creative Commons licence and your intended use is not permitted by statutory regulation or exceeds the permitted use, you will need to obtain permission directly from the copyright holder. To view a copy of this licence, visit http://creativecommons.org/licenses/by/4.0/ The Creative Commons Public Domain Dedication waiver (http://creativecommons.org/publicdomain/zero/1.0/) applies to the data made available in this article, unless otherwise stated in a credit line to the data. 
biofilms formed by periodontopathogenic bacteria prevents a variety of diseases. However, oral care by brushing has been insufficient in healthy adults, much less infants and the elderly. Denture wearing and treatment by an orthodontist may also be insufficient. Although physical methods are fundamental for removing oral biofilms, there is a wide variation in its efficiency due to individual differences. Anti-bacterial agents and disinfectants are effective against planktonic bacteria (bacteria suspended in liquid), however, they are not effective against biofilm-forming bacteria due to the difficulty of chemicals penetrating the biofilm. Hence, there is concern about the risk of the emergence of resistant bacteria, such as the formation of persister cells [15-18]. Oral pathogens that form persisters may cause recurrence of oral diseases via regrowth. Therefore, inhibiting the growth of oral pathogens, as well as effectively preventing biofilm formation contribute to reducing these risks. Thus, there is a requirement for the development of a simpler and more effective oral care capable of inhibiting oral bacterial growth and biofilm formation.

EPS is a basic component of biofilms comprising polysaccharides, enzymes, DNA, lipids, and various other factors $[19,20]$, which determine the physicochemical properties of biofilms formed by bacteria $[21,22]$. Strains such as Pseudomonas aeruginosa produce biosurfactants, including rhamnolipids [23]. Rhamnolipids have a rhamnose sugar moiety and are linked to alkanoic acid fatty acid tails such as myrmicacin [24]. Rhamnolipids exhibit cytotoxicity as hemolysins [25], and participate in bacterial communication as a quorum-sensing substance [26]. They have also been found to be dispersed in the biofilms of various bacteria, such as Bordetella bronchiseptica [27] and Desulfovibrio vulgaris [28]. Surfactin is another type of biosurfactant secreted by Bacillus subtilis [29]. Its structure includes a hydrophilic cyclic peptide consisting of seven amino acids and a hydrophobic hydrocarbon chain [30]. Surfactin is a signaling molecule that initiates biofilm formation [29]. In contrast, there is a report that surfactin inhibits biofilms of Salmonella enterica [31]. Hence, both of these types of biosurfactants are associated with bacterial biofilm formation. Therefore, it can be hypothesized that they have significant inhibitory effects against biofilms formed by oral pathogenic bacteria.

However, inhibiting oral pathogenic bacterial growth and biofilm formation is important not only for suppressing oral diseases, but also for ameliorating systemic diseases. Therefore, in this study, we investigated the inhibitory effects of biosurfactants (rhamnolipids and surfactin) against bacterial growth, and biofilm formation by $A$. actinomycetemcomitans
Y4, S. mutans UA159, and S. sanguinis ATCC10556. Further, we investigated which process required for biofilm formation (attachment, initiation, or maturation) is inhibited by biosurfactants.

\section{Results \\ Rhamnolipids and surfactin exhibit variable inhibitory effects on bacterial cell growth}

First, the ability of rhamnolipids and surfactin to inhibit the growth of bacteria was investigated. The results showed that rhamnolipids significantly inhibited the growth of $S$. mutans UA159 and $S$. sanguinis ATCC10556, however, A. actinomycetemcomitans Y4 was not affected (Fig. 1a-c). Rhamnolipids completely inhibited the growth of $A$. actinomycetemcomitans $\mathrm{Y} 4$ at a concentration of $3.25 \mathrm{w} / \mathrm{v} \%$ (Fig. 1a). However, rhamnolipids inhibited both $S$. mutans UA159 and S. sanguinis ATCC10556 growth at concentrations $>1.59 \times 10^{-3}$ $\mathrm{w} / \mathrm{v} \%$, whereas these two bacterial species were nearly completely inhibited at $3.25 \mathrm{w} / \mathrm{v} \%$ and $6.35 \times 10^{-3} \mathrm{w} / \mathrm{v} \%$ rhamnolipid, respectively (Fig. $1 \mathrm{~b}$ and c). Alternatively, surfactin exhibited the highest inhibitory effect on $S$. sanguinis ATCC10556, whereas no effect was observed on A. actinomycetemcomitans Y4 and S. mutans UA159 (Fig. 1d-f). Moreover, high concentrations of surfactin promoted A. actinomycetemcomitans Y4 and S. mutans UA159 growth, rather than inhibited it (Fig. 1d and e). Nevertheless, at a concentration $>1.26 \times 10^{-3} \mathrm{w} / \mathrm{v} \%$, surfactin inhibited S. sanguinis ATCC10556 growth, with near complete inhibition observed at $0.01 \mathrm{w} / \mathrm{v} \%$ (Fig. 1f).

\section{Biosurfactants exhibit variable inhibitory effects on biofilm formation}

The inhibitory capacity of biosurfactants on biofilm formation is depicted in Fig. 2. At $3.17 \times 10^{-3} \mathrm{w} / \mathrm{v} \%$, rhamnolipids exhibited inhibitory effects against $A$. actinomycetemcomitans $\mathrm{Y} 4$ biofilm formation, while at $0.013 \mathrm{w} / \mathrm{v} \%$, biofilm formation was inhibited by $93 \%$ (Fig. 2a). Interestingly, although $A$. actinomycetemcomitans Y4 growth was not inhibited at rhamnolipid concentrations $<0.81 \mathrm{w} / \mathrm{v} \%$, biofilm formation was inhibited from $0.81 \mathrm{w} / \mathrm{v} \%$ to $3.17 \times 10^{-3} \mathrm{w} / \mathrm{v} \%$ (Figs. 1a and $2 \mathrm{a}$ ). Hence, low concentrations of rhamnolipids were capable of only inhibiting biofilm formation without affecting bacterial growth. In case of $S$. mutans UA159, rhamnolipids at a concentration of $6.35 \times 10^{-3} \mathrm{w} / \mathrm{v} \%$ inhibited biofilm formation, however, near complete inhibition was observed at $0.1 \mathrm{w} / \mathrm{v} \%$ (Fig. 2b). Meanwhile, in $S$. sanguinis ATCC10556, rhamnolipids completely inhibited biofilm formation at a concentration of $6.35 \times 10^{-3} \mathrm{w} / \mathrm{v} \%$. Alternatively, rhamnolipids promoted biofilm formation (2fold) at $1.98 \times 10^{-4} \mathrm{w} / \mathrm{v} \%$ (Fig. 2c). Furthermore, approximately $90 \%$ of $A$. actinomycetemcomitans Y4 biofilm formation was inhibited at surfactin concentration 


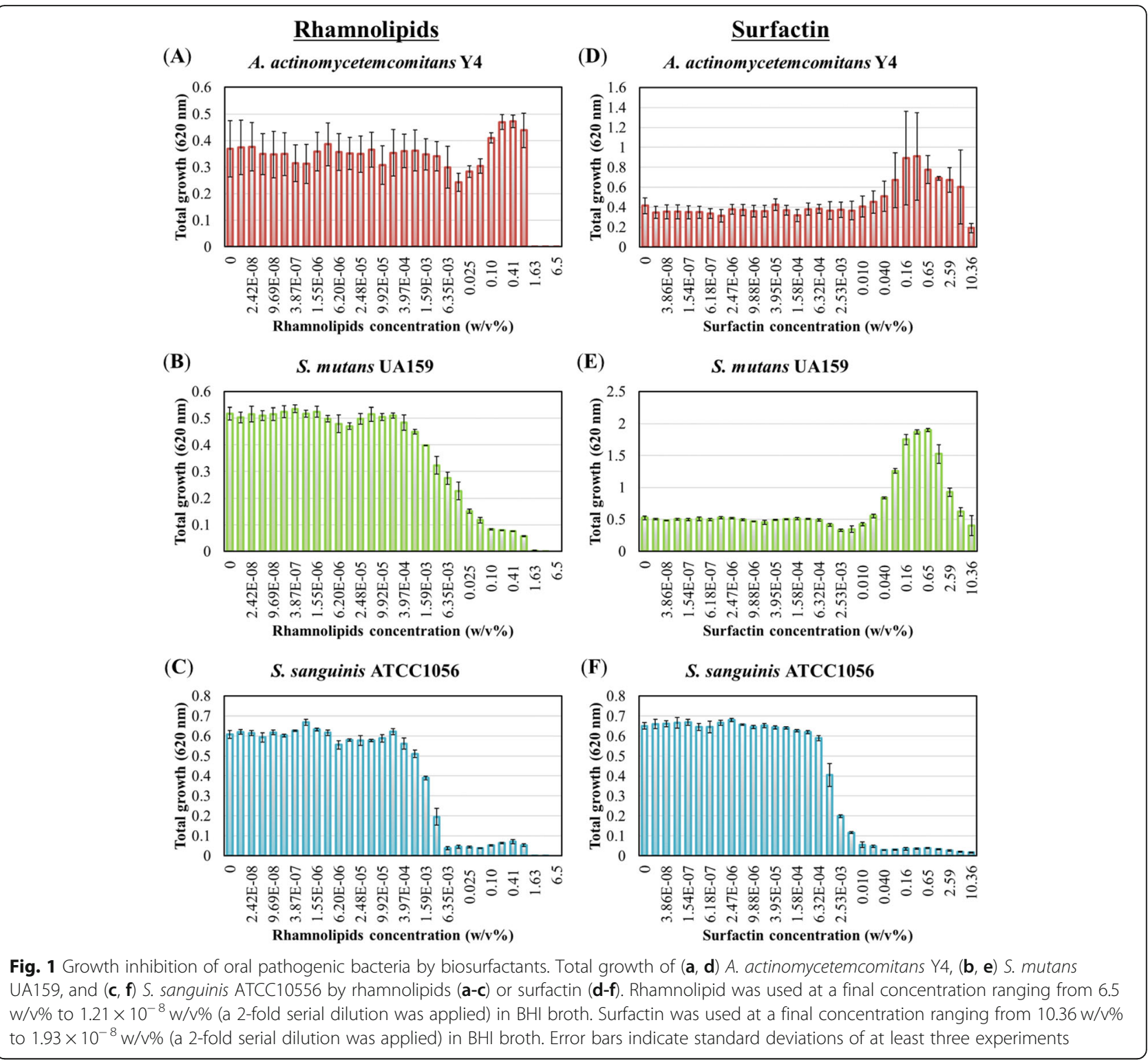

of $10.36 \mathrm{w} / \mathrm{v} \%$. However, $2.53 \times 10^{-3} \mathrm{w} / \mathrm{v} \%$ to $2.59 \mathrm{w} / \mathrm{v} \%$ promoted $A$. actinomycetemcomitans Y4 biofilm formation by up to 6-fold (Fig. 2d). Meanwhile, treatment of $S$. mutans UA159 with surfactin promoted biofilm formation with no inhibitory effect observed at any concentration (Fig. 2e). Finally, concentrations $>2.53 \times 10^{-3} \mathrm{w} / \mathrm{v} \%$ of surfactin caused near complete inhibition of S. sanguinis ATCC10556 biofilm formation (Fig. 2f).

\section{Scanning electron microscopy and confocal microscopy analyses confirm the effect of biosurfactants on biofilm formation}

Next, the thickness of the oral pathogenic bacterial biofilms with or without biosurfactant treatment $(0.65 \mathrm{w} / \mathrm{v} \%$ rhamnolipids and $1.04 \mathrm{w} / \mathrm{v} \%$ surfactin) was estimated by scanning electron microscopy (SEM) (Fig. 3) and confocal microscopy (Supplemental Fig. 1). As shown in the
SEM images, untreated $A$. actinomycetemcomitans Y4, $S$. mutans UA159, and S. sanguinis ATCC10556 formed thick biofilms $(3-25 \mu \mathrm{m}$; Fig. 3a-c). Meanwhile, at a concentration of $0.65 \mathrm{w} / \mathrm{v} \%$ rhamnolipid, biofilm formation by $A$. actinomycetemcomitans $\mathrm{Y} 4$ and $S$. sanguinis ATCC10556 was almost completely inhibited (Fig. 3d and f) and that of $S$. mutans UA159 was moderately inhibited (Fig. 3e). Surfactin at $1.04 \mathrm{w} / \mathrm{v} \%$ induced high levels of inhibition against S. sanguinis ATCC10556 biofilm formation (Fig. 3i); however, it did not show an inhibitory effect against $A$. actinomycetemcomitans $\mathrm{Y} 4$ and S. mutans UA159 biofilm formation (Fig. $3 g$ and $h$ ).

Observations from all fluorescence confocal microscopy images (Supplemental Fig. 1) were in concordance with the SEM results. Similar tendencies were observed when comparing Figs. 2 and 3. 
Rhamnolipids

(A)

A. actinomycetemcomitans Y4

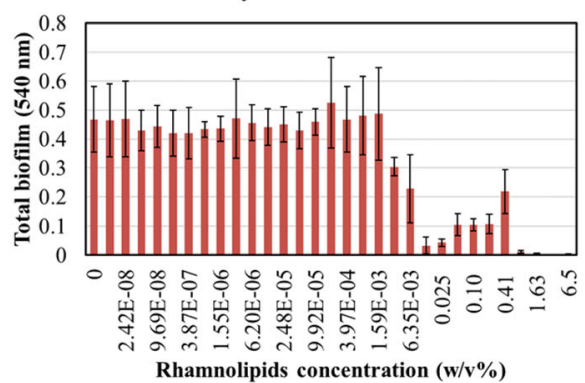

(B)

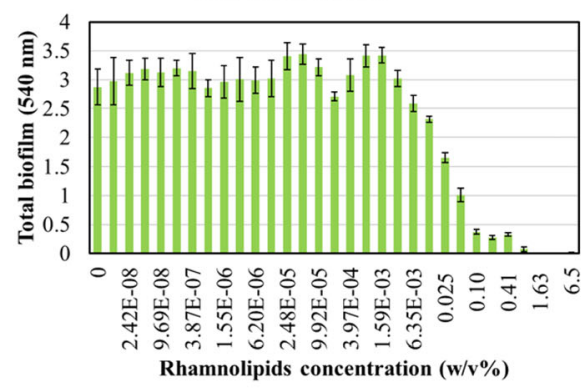

(C)

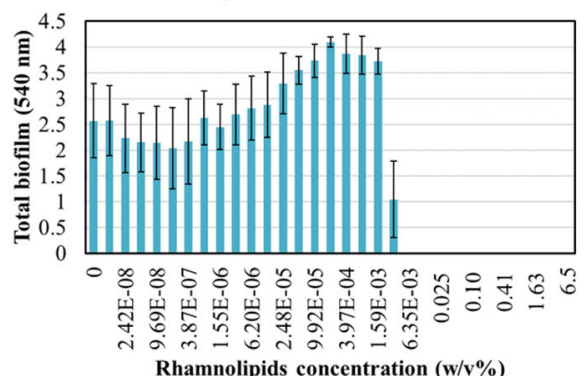

Surfactin

(D) A. actinomycetemcomitans Y4

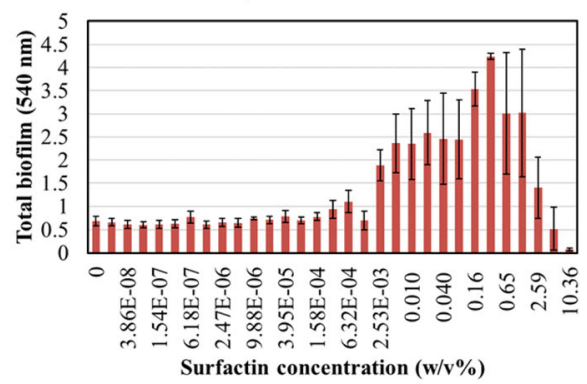

(E)



(F) S. sanguinis ATCC1056

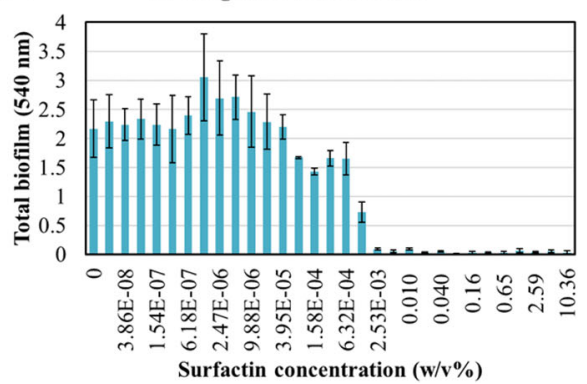

Fig. 2 Inhibition of biofilm formation by biosurfactants. Total biofilm formation of (a, d) A. actinomycetemcomitans Y4, (b, e) S. mutans UA159, and (c, f) S. sanguinis ATCC10556 by rhamnolipids (a-c) or surfactin (d-f). Rhamnolipids was used at a final concentration ranging from $6.5 \mathrm{w} / \mathrm{v} \%$ to $1.21 \times 10^{-8} \mathrm{~W} / \mathrm{V} \%$ (a 2 -fold serial dilution was applied) in $\mathrm{BHI}$ broth. Surfactin was used at a final concentration ranging from $10.36 \mathrm{~W} / \mathrm{v} \%$ to $1.93 \times 10^{-8} \mathrm{~W} / \mathrm{V} \%$ (a 2 -fold serial dilution was applied) in BHI broth. Error bars indicate standard deviations of at least three experiments

\section{To determine the step of biofilm formation inhibited by rhamnolipids}

To investigate the step of biofilm formation the rhamnolipids exert their inhibitory effect on (attachment, initiation, or maturation process), pre-treatment for the attachment process and dispersal for the maturation process were performed. As rhamnolipids exhibited the highest inhibitory effect against A. actinomycetemcomitans Y4 biofilm formation (Fig. 2a), rhamnolipidtreatment conditions were examined. As observed earlier, rhamnolipids affected the step of biofilm formation between initiation (after attachment) and maturation as it was co-cultured with rhamnolipids (Fig. 4a left $=$ Fig. 2a). Rhamnolipids exhibited inhibitory effects against $A$. actinomycetemcomitans Y4 biofilm formation at $3.17 \times$ $10^{-3} \mathrm{w} / \mathrm{v} \%$. Significant inhibitory effects were observed beginning at $0.013 \mathrm{w} / \mathrm{v} \%$ of rhamnolipids (Fig. 4a left, black arrow). Although A. actinomycetemcomitans Y4 biofilm was observed by SEM after rhamnolipid treatment at this concentration, biofilms were nearly completely inhibited (Fig. 4a right). Meanwhile, Fig. 4b presents the results of the rhamnolipid pre-treatment test, wherein the attachment process was investigated. Specifically, plates were pre-treated with rhamnolipids, after which the attachment of bacteria was detected. At concentrations higher than $0.81 \mathrm{w} / \mathrm{v} \%$, pre-treatment with rhamnolipids inhibited $A$. actinomycetemcomitans Y4 biofilm formation, however, $<0.41 \mathrm{w} / \mathrm{v} \%$ did not elicit an effect (Fig. 4b left). The SEM image (Fig. 4b right) indicated that pretreatment at $0.013 \mathrm{w} / \mathrm{v} \%$ of rhamnolipids resulted in no inhibition on biofilm formation. Next, the effect of rhamnolipids on the maturation of $A$. actinomycetemcomitans 




Y4 biofilms was investigated. In this assay, rhamnolipids were added to the biofilm after $24 \mathrm{~h}$ of culturing; hence the biofilm was already established with attachment and initiation having already occurred. This assay, therefore, examined the effect on the final stage of the biofilm life cycle, i.e., dispersion, during which cells leave the biofilm to become planktonic, thereby making themselves more susceptible to antimicrobials. Results show that although rhamnolipids induced biofilm dispersal at concentrations $>0.1 \mathrm{w} / \mathrm{v} \%$, this effect was not observed at concentrations $<0.05 \mathrm{w} / \mathrm{v} \%$ (Fig. 4c left). This effect on dispersal was also observed by SEM after treatment with $0.013 \mathrm{w} / \mathrm{v} \%$ rhamnolipid, whereby the biofilms were not removed (Fig. 4c right).

\section{Discussions}

In this study, we investigated the effect of biosurfactants (rhamnolipids and surfactin) on the growth of pathogenic bacteria and biofilm formation. The results showed that rhamnolipids showed high anti-bacterial and anti-biofilm effects against oral bacteria, particularly Streptococcus spp. (Figs. 1a-c and 2a-c). Similarly, numerous previous studies have reported anti-bacterial and anti-biofilm activities of rhamnolipids. For example, Listeria monocytogenes growth is reportedly inhibited at a concentration of $0.25 \mathrm{w} / \mathrm{v} \%$ [32]. Meanwhile, growth inhibition has been reported for Bacillus cereus and Staphylococcus aureus at $6.4 \times 10^{-3} \mathrm{w} / \mathrm{v} \%$ and $25.6 \times$ $10^{-3} \mathrm{w} / \mathrm{v} \%$ of rhamnolipids [33]. Additionally, for various bacterial pathogens including Enterobacter aerogenes and Klebsiella pneumoniae, growth inhibition was noted at concentrations ranging from $0.5 \times 10^{-3} \mathrm{w} / \mathrm{v} \%$ to $0.25 \mathrm{w} / \mathrm{v} \%$ [34-37]. Herein, the growth of A. actinomycetemcomitans Y4, S. mutans UA159, and S. sanguinis ATCC10556 was completely inhibited at $3.25 \mathrm{w} / \mathrm{v} \%, 3.25$ $\mathrm{w} / \mathrm{v} \%$, and $6.35 \times 10^{-3} \mathrm{w} / \mathrm{v} \%$, respectively (Fig. 1a-c). 

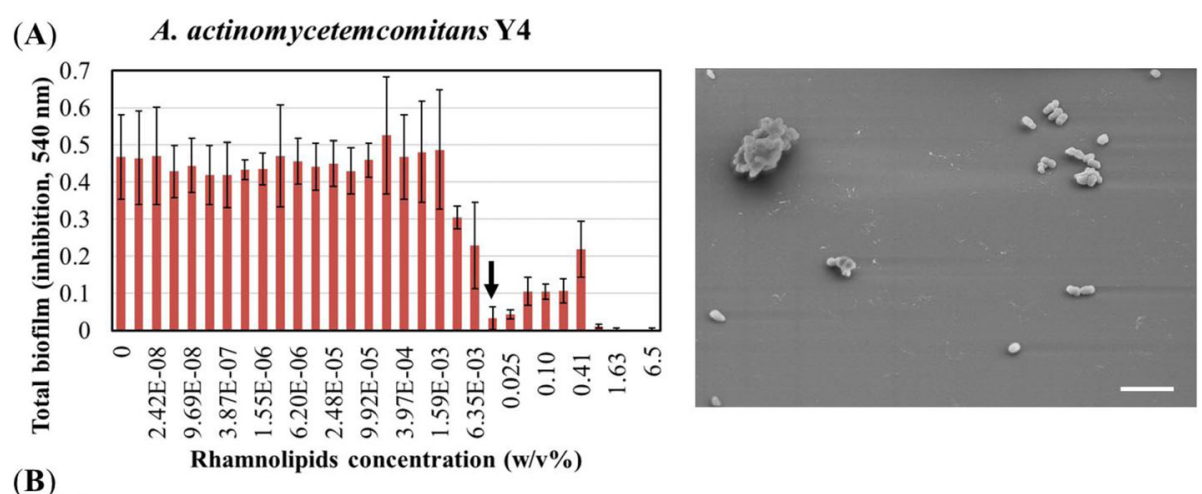

(B)

Rhamnolipids concentration $(\mathbf{w} / \mathbf{v} \%)$
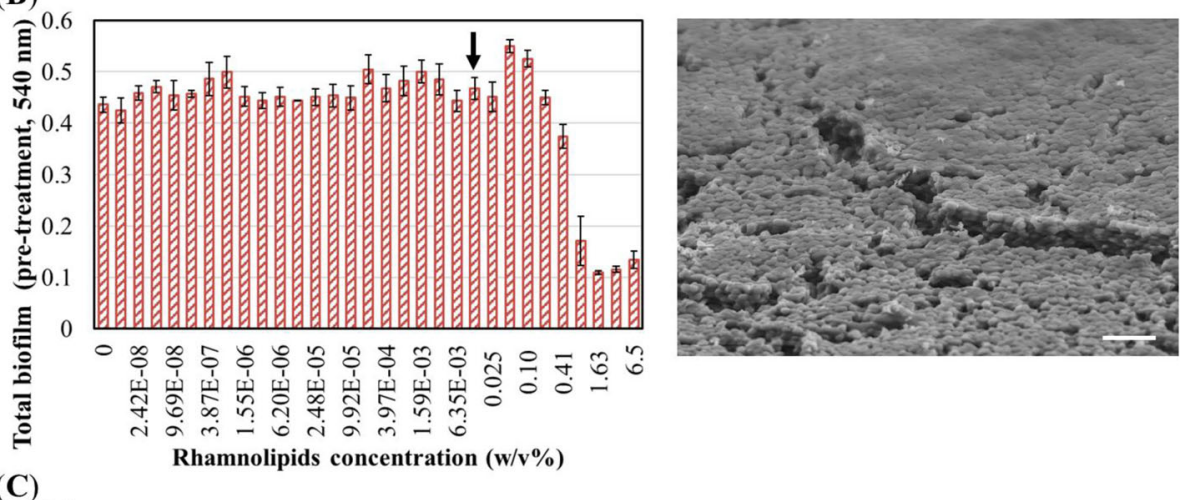

(C)
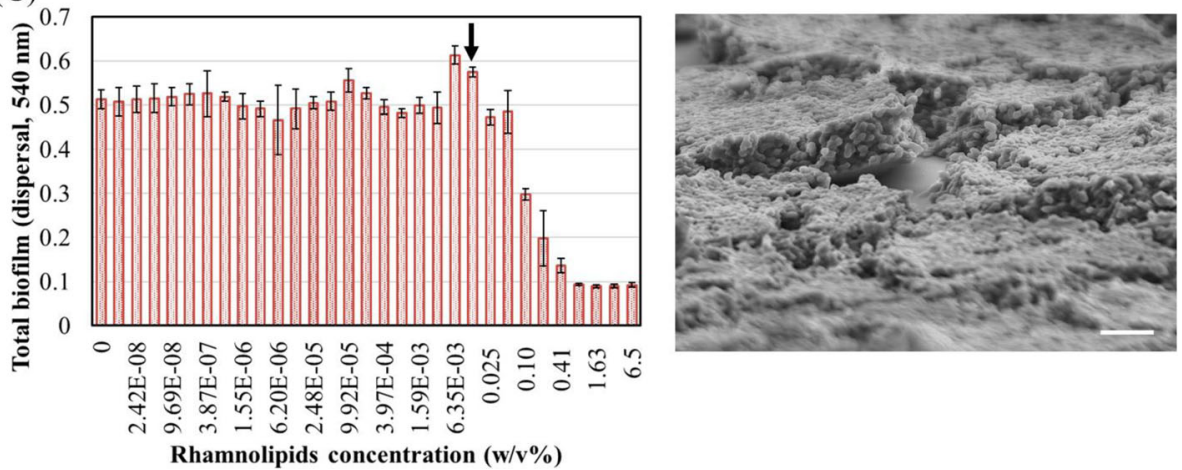

Fig. 4 Effect of rhamnolipids on each step of biofilm formation. a Graphical representation of the total biofilm formed by A. actinomycetemcomitans Y4 treated with rhamnolipids (same as Fig. 2a). The image on the right shows SEM image of A. actinomycetemcomitans Y4 biofilms after incubation with 0.013 w/v\% rhamnolipid. b Graphical representation of the total A. actinomycetemcomitans Y4 biofilm formed on pre-treated rhamnolipid microtiter plate. This assay demonstrates inhibition of the attachment step of biofilm formation. The image on the right shows SEM image of $A$. actinomycetemcomitans Y4 biofilm upon pre-treatment with $0.013 \mathrm{w} / \mathrm{v} \%$ rhamnolipid. c Graphical representation of the total A. actinomycetemcomitans Y4 biofilm formed after rhamnolipid dispersal. This assay demonstrates the effect of rhamnolipids against matured biofilm. The image on the right shows SEM images of A. actinomycetemcomitans Y4 biofilms after dispersal treatment with $0.013 \mathrm{~W} / \mathrm{V} \%$ rhamnolipid. Black arrows indicate the rhamnolipid concentration that exhibited highest inhibitory effect in (a) $(0.013 \mathrm{w} / \mathrm{V} \%)$. Error bars indicate standard deviations of at least three experiments. Scale bars indicate $3 \mu \mathrm{m}$

Hence, rhamnolipids exhibited high inhibitory effects against the growth of cariogenic bacteria.

Furthermore, an anti-biofilm effect of rhamnolipids has been previously reported for Pseudomonas aeruginosa at $5 \times 10^{-3} \mathrm{w} / \mathrm{v} \%$ [38]. Similarly, a $60 \%$ inhibitory effect was observed for Staphylococcus capitis and Bacillus licheniformis at a rhamnolipid concentration of $4 \times 10^{-3} \mathrm{w} / \mathrm{v} \%$ [39]. Meanwhile, our current results demonstrated that rhamnolipids inhibited A. actinomycetemcomitans Y4 biofilm formation by $93 \%$ at $0.013 \mathrm{w} / \mathrm{v} \%$, (Fig. 2a), and inhibited S. mutans UA159 by $87 \%$ at $0.1 \mathrm{w} / \mathrm{v} \%$ (Fig. $2 \mathrm{~b}$ ). Additionally, S. sanguinis ATCC10556 biofilm formation was completely inhibited at concentrations $>6.35 \times 10^{-3}$ $\mathrm{w} / \mathrm{v} \%$ (Fig. 2c). Hence, we confirmed that all examined oral pathogenic bacteria were inhibited by rhamnolipids at concentrations similar to those previously reported. Moreover, considering that rhamnolipids also inhibited the growth of S. mutans UA159 and S. sanguinis ATCC10556, 
the inhibitory effect on biofilms was likely due to bacterial growth inhibition (Fig. 1a-c). Alternatively, rhamnolipids inhibited A. actinomycetemcomitans Y4 biofilm formation, however, they did not inhibit bacterial growth at concentrations ranging from $3.17 \times 10^{-3} \mathrm{w} / \mathrm{v} \%$ to $0.81 \mathrm{w} / \mathrm{v} \%$ (Figs. 1a and 2a). Therefore, rhamnolipids likely directly inhibited $A$. actinomycetemcomitans Y4 biofilm formation. However, the potential of rhamnolipids to inhibit A. actinomycetemcomitans Y4 biofilm formation decreased at $0.41 \mathrm{w} / \mathrm{v} \%$, which was confirmed in six different experimental replicates. Although the precise cause of this result is unknown, it is apparent that only specific concentrations of rhamnolipids elicit inhibitory effects on A. actinomycetemcomitans Y4 biofilm formation.

A number of studies have also reported anti-bacterial and anti-biofilm activity of surfactin toward various bacteria. For example, growth inhibition of Staphylococcus epidermidis was reported at a surfactin concentration of $0.625 \mathrm{w} / \mathrm{v} \%$ [40]. Additionally, $0.5 \times 10^{-3} \mathrm{w} / \mathrm{v} \%$ of surfactin inhibited the growth of sulfate-reducing bacteria (Desulfovibrio alaskensis) [41]. Herein, we confirmed that surfactin inhibits growth of specific oral pathogens, particularly $S$. sanguinis ATCC10556 (Fig. 1f). At concentrations > $1.26 \times 10^{-3} \mathrm{w} / \mathrm{v} \%$, surfactin inhibited $S$. sanguinis ATCC10556 growth; moreover, nearly complete inhibition was observed at $0.01 \mathrm{w} / \mathrm{v} \%$, indicating that surfactin is capable of inhibiting bacterial species to a level similar to that previously reported [40, 41]. However, surfactin also caused growth promotion of A. actinomycetemcomitans Y4 and S. mutans UA159 (Fig. 1d and e). Production of surfactin by Bacillus subtilis serves to enhance bacterial growth and for biological control activity via direct antagonism of pathogens [29]. Moreover, considering that the structure of surfactin contains a peptide chain [30], it may function as a nutrient and growth promotor.

The anti-biofilm activity of surfactin has also been demonstrated against various bacteria. For example, $6.6 \times 10^{-3} \mathrm{w} / \mathrm{v} \%$ of surfactin eliminated Legionella pneumophila biofilms [42]. Surfactin also reportedly inhibits the formation of L. monocytogenes, Enterobacter sakazakii, and Salmonella Enteritidis biofilms on stainless steel and polypropylene surfaces [43]. Herein, we found that surfactin only inhibited biofilm formation of specific oral pathogens. Nearly $100 \%$ of S. sanguinis ATCC10556 biofilm formation was inhibited by $2.53 \times 10^{-3} \mathrm{w} / \mathrm{v} \%$ surfactin treatment (Fig. 2f). However, no inhibitory effect was observed in the other two oral bacteria (A. actinomycetemcomitans Y4 and S. mutans UA159), rather an enhancing effect was noted (Fig. $2 \mathrm{~d}$ and e). We, therefore, postulate that surfactin enhanced biofilm formation by these two bacterial species via enhancing the growth of the individual cells, as described earlier.

To identify which biofilm process was inhibited by biosurfactants, the attachment and maturation steps were assessed. A number of previous studies have indicated that pre-treatment with rhamnolipids effectively inhibits biofilm formation. For example, pre-treatment of polystyrene surfaces with $1 \mathrm{w} / \mathrm{v} \%$ rhamnolipids caused a 58 and $68 \%$ inhibitory effect on the formation of $L$. monocytogenes and $S$ aureus biofilms, respectively [44]. Additionally, the adhesion of $B$. licheniformis was inhibited by $85 \%$ following pre-treatment with $9 \times 10^{-3} \mathrm{w} / \mathrm{v} \%$ rhamnolipids [39]. Herein, we observed that pre-treatment with $>0.81 \mathrm{w} / \mathrm{v} \%$ rhamnolipids effectively inhibited more than $63 \%$ of A. actinomycetemcomitans Y4 biofilm formation (Fig. 4b left), thereby confirming its inhibitory effect on the attachment process. Although rhamnolipids inhibited more than $90 \%$ of A. actinomycetemcomitans Y4 biofilm formation at $0.013 \mathrm{w} / \mathrm{v} \%$ (Fig. 4a left, black arrow), pretreatment with $0.013 \mathrm{w} / \mathrm{v} \%$ resulted in no inhibitory effect (Fig. 4b left, black arrow and right SEM image). Therefore, it may be inferred that the inhibitory effect exhibited by rhamnolipids does not interfere with bacterial cell adhesion. Next, the dispersal effect of rhamnolipids on mature biofilms was investigated. Previous reports employing a rhamnolipid-deficient bacterial strain demonstrated the role of rhamnolipid on biofilm dispersal. The authors observed that biofilms formed by sulfate-reducing bacteria can be dispersed by rhamnolipids present in the supernatant of Pseudomonas aeruginosa PA14 [28, 45]. The current study demonstrated $43-83 \%$ biofilm dispersion following treatment with $>0.1 \mathrm{w} / \mathrm{v} \%$ rhamnolipids. However, $0.013 \mathrm{w} / \mathrm{v} \%$ rhamnolipids did not impact maturation of the biofilm (Fig. 4c left, black arrow and SEM image on the right panel). Therefore, the primary effect exhibited by rhamnolipids does not appear to be associated with the maturation process. Taken together, these results indicate that the inhibitory effect of biosurfactants, specifically, rhamnolipids, toward the formation of biofilms by oral pathogenic bacteria, targets a stage after attachment, from initiation to maturation. Moreover, considering that $A$. actinomycetemcomitans $\mathrm{Y} 4$ grew well following treatment with $0.013 \mathrm{w} / \mathrm{v} \%$ rhamnolipids, in spite of the inhibition of biofilm formation (Fig. 2a), the antibiofilm effect was not dependent on bactericidal activity. However, the quorum-sensing system is strongly associated with biofilm maturation and dispersion [46, 47]. Specifically, autoinducer-2, known as the only quorum-sensing molecule in A. actinomycetemcomitans, is closely related to biofilm formation [48-50]. Hence, biosurfactants may interfere with the quorumsensing system by suppressing biofilm formation. However, the specific details regarding this mechanism require further investigation. Specifically, the use of bacterial strains deficient in various quorumsensing molecules, including quormones, may serve to further decipher the mechanism by which biosurfactants affect quorum-sensing and biofilm formation. 
Currently, there is need for improved oral health practices to reduce the growth of pathogenic oral bacteria and associated biofilms. To this end, various kinds of compound (chlorhexidine [51], povidone iodine [52], hydrogen peroxide [53], acidified sodium chlorite [54], and cetylpyridinium chloride [55]) are used as mouthwash agents. However, these compounds have various associated risks, including diabetes [56] and oral cancer [57]. Moreover, chlorhexidine has reportedly caused anaphylaxis [58], whereas oral ulcerations have been observed following the use of hydrogen peroxide [59]. Furthermore, acidified sodium chlorite has been reported to cause enamel erosion similar to orange juice [60], and cetylpyridinium chloride induces cell death via the apoptotic pathway [61]. Hence, components of common mouthwash agents have adverse side effects associated with them. Alternatively, biosurfactants (rhamnolipids and surfactin) have low toxicity and are eco-friendly [62, 63], and may, therefore, provide a superior option for improved oral care. Rhamnolipids, specifically, may serve as an optimal choice as a preventive medicine for periodontal disease as it demonstrated strong anti-bacterial and anti-biofilm activity against $A$. actinomycetemcomitans Y4.

There are some limitations to this study. First, the mechanisms of inhibition of growth and biofilm formation by biosurfactants were not elucidated. We suggested that the inhibitory activity of rhamnolipids against $A$. actinomycetemcomitans $\mathrm{Y} 4$ does not involve the attachment and maturation process of biofilm formation. However, the exact mechanism and step at which the process is inhibited remains unclear. To overcome this limitation, mutants for biofilmassociated genes may be employed to investigate the mechanism of biofilm inhibition. Additionally, the relationship between quorum-sensing molecules and biosurfactants may be deduced as quorum-sensing system is closely related to biofilm formation. Second, the oral cavity is a complex environment, comprising of a wide variety of bacterial species either as planktonic cells or incorporated into biofilms. In the present study, we demonstrated the effect of biosurfactants toward a single strain of cariogenic and periodontopathic bacteria. It is also important to conduct experiments in an environment closer to the oral cavity to verify the combined effect of the gamut of bacterial flora present in this region. In-depth analysis regarding the associated risks of using biosurfactants in the oral cavity, including clinical trials, are required to verify their safety profile. Clinical studies on healthy subjects or patients with localized invasive periodontitis caused by $A$. actinomycetemcomitans Y4 are warranted to validate biosurfactants as a medicine for periodontal disease.

\section{Conclusion}

In this study, we demonstrated the inhibitory effect of biosurfactants (rhamnolipids and surfactin) against oral bacterial pathogens. Specifically, we found that rhamnolipids exhibited both anti-bacterial and anti-biofilm activity against $A$. actinomycetemcomitans Y4. Both biosurfactants showed a high inhibitory effect against $S$. sanguinis ATCC10556 growth. Rhamnolipids showed high inhibitory effect against growth of $S$. mutans UA159 and S. sanguinis ATCC10556 and high biofilm inhibitory effects against $A$. actinomycetemcomitans Y4. In addition, we propose that rhamnolipids primarily interfere with $A$. actinomycetemcomitans Y4 biofilm formation after the attachment or maturation step. However, elucidation of the detailed mechanism is required. Owing to their low toxicity and eco-friendly properties, rhamnolipids and surfactin can serve as potential medications for the treatment and prevention of oral diseases. From this study, we suggest the possibility of rhamnolipids to be used as a preventive agent for localized invasive periodontitis caused by A. actinomycetemcomitans Y4.

\section{Methods}

\section{Bacteria cultivation}

The strains used in this study are listed in Table 1. A. actinomycetemcomitans Y4, S. mutans UA159, and S. sanguinis ATCC10556 were cultured in brain heart infusion broth (BHI: Becton Dickinson, Heidelberg, Germany) containing $1 \%(\mathrm{w} / \mathrm{v})$ yeast extract at $37^{\circ} \mathrm{C}$ in a $5 \% \mathrm{CO}_{2}$ atmosphere.

\section{Biofilm assay with biosurfactant}

Rhamnolipids (AGAE Technologies, LLC, OR, USA) and sodium surfactin (Kaneka, Osaka, Japan) were dissolved into BHI medium at concentrations of 6.5 and $10.36 \mathrm{w} /$ $\mathrm{v} \%$, respectively. A series of 2 -fold serial dilution solutions were prepared into 96 -well microtiter plate (i.e. in case of rhamnolipids, first rows are $6.5 \mathrm{w} / \mathrm{v} \%$, second rows are $3.25 \mathrm{w} / \mathrm{v} \%$, third rows are $1.63 \mathrm{w} / \mathrm{v} \%$, and last rows are $\left.1.21 \times 10^{-8} \mathrm{w} / \mathrm{v} \%\right)$. Sucrose $(0.1 \mathrm{w} / \mathrm{v} \%)$ for $S$. mutans UA159, and $1 \mathrm{w} / \mathrm{v} \%$ sucrose for S. sanguinis ATCC10556 were added to all wells to form biofilms (Supplemental Fig. 2). A saturated culture of each oral strain was inoculated into all wells to a turbidity of 0.05 at $600 \mathrm{~nm}$, except for the blank. These plates were incubated at $37^{\circ} \mathrm{C}$ in a $5 \% \mathrm{CO}_{2}$ atmosphere for $24 \mathrm{~h}$ to form

Table 1 Bacterial strains used in this study

\begin{tabular}{ll}
\hline Strains & Source \\
\hline A. actinomycetemcomitans Y4 & ATCC43718 [64] \\
S. mutans UA159 & ATCC700610 [65] \\
S. sanguinis ATCC10556 & ATCC10556 \\
\hline
\end{tabular}


biofilms. After $24 \mathrm{~h}$ incubation, total growth was measured at $620 \mathrm{~nm}$. Next, the supernatant was discarded, and the plate was washed with $\mathrm{dH}_{2} \mathrm{O} 3$ times to remove planktonic cells. Crystal violet $(0.1 \%)$ was added to stain the biofilm for $20 \mathrm{~min}$ and subsequently removed by washing the plate with $\mathrm{dH}_{2} \mathrm{O} 3$ times; next, 95\% ethanol was added. After a $5 \mathrm{~min}$ incubation, the plate was measured at an absorbance of $540 \mathrm{~nm}$ using a microplate reader (Multiskan FC, Thermo Fisher Scientific, Waltham, MA, USA).

\section{Microscopic observation of oral biofilms}

SEM (S-4300, HITACHI, Tokyo, Japan) and confocal microscope (BZ-X800, Keyence, Osaka, Japan) were employed to observe each oral pathogenic bacterial biofilm. Oral pathogenic bacteria with or without biosurfactants were incubated into ibidi $\mu$-Plate 96 square well plate (NIPPON Genetics Co., Ltd., Tokyo, Japan) at $37^{\circ} \mathrm{C}$ in a $5 \% \mathrm{CO}_{2}$ atmosphere for $24 \mathrm{~h}$ to form biofilms. The supernatant was discarded, and the plate was washed with $\mathrm{dH}_{2} \mathrm{O} 3$ times to remove planktonic cells. Glutaraldehyde was used as a fixative for biofilms to prepare SEM observation samples. Biofilms were dehydrated by ethanol gradient (50, 70, 90, 99, and $100 \%$ anhydrous with molecular sieves). After dehydration, ethanol was replaced by t-butanol and freeze dried at $20^{\circ} \mathrm{C}$. Frosted t-butanol was sublimated by lyophilization. The biofilm sample was then coated by Pt spattering (Magnetron sputter MSP-1S, Vacuum Device Inc., Ibaraki, Japan). Accelerating voltages were performed at $5.0 \mathrm{kV}$ and magnifications were adjusted X350-6000. To prepare the confocal microscopy samples, biofilms were stained with SYTO9 for $15 \mathrm{~min}$ in the dark. Biofilms were washed with PBS and air-dried in the dark at room temperature. The excitation wavelength of SYTO9 was $450-490 \mathrm{~nm}$, and the emission was $500-550 \mathrm{~nm}$. The fluorescence images were analyzed using the BZ-H4A software (Keyence, Osaka, Japan).

\section{Biofilm pre-treatment and dispersal assay}

For pre-treatment with rhamnolipids, $200 \mu \mathrm{L}$ of rhamnolipids dissolved in 1X PBS (concentration ranging from $6.5 \mathrm{w} / \mathrm{v} \%$ to $1.21 \times 10^{-8} \mathrm{w} / \mathrm{v} \%$ ) were added into a 96 -well microtiter plate and incubated at $37^{\circ} \mathrm{C}$ in a $5 \% \mathrm{CO}_{2}$ atmosphere for $1 \mathrm{~h}$. As a control, $200 \mu \mathrm{L}$ of $1 \mathrm{X}$ PBS was used (i.e. $0 \mathrm{w} / \mathrm{v} \%$ ). Rhamnolipids solutions were discarded and $200 \mu \mathrm{L}$ of $A$. actinomycetemcomitans $\mathrm{Y} 4 \mathrm{cul}-$ ture $\left(\mathrm{OD}_{600} \sim 0.05\right)$ was added into all pre-treated wells. After $24 \mathrm{~h}$ incubation at $37^{\circ} \mathrm{C}$ in a $5 \% \mathrm{CO}_{2}$ atmosphere, biofilm assays were performed using the same method as mentioned above.

To investigate biofilm dispersal, $200 \mu \mathrm{L}$ of A. actinomycetemcomitans $\mathrm{Y} 4$ culture $\left(\mathrm{OD}_{600} \sim 0.05\right)$ was added into a 96-well microtiter plate and incubated at $37^{\circ} \mathrm{C}$,
$5 \% \mathrm{CO}_{2}$ for $24 \mathrm{~h}$. The supernatant was discarded and washed with $\mathrm{dH}_{2} \mathrm{O}$ thrice to remove planktonic cells. Rhamnolipids dissolved in $1 \mathrm{X}$ PBS $(200 \mu \mathrm{L}$ each and concentration ranging from $6.5 \mathrm{w} / \mathrm{v} \%$ to $1.21 \times 10^{-8} \mathrm{w} /$ $\mathrm{v} \%$, and $0 \mathrm{w} / \mathrm{v} \%$ as a control) were added into 96 -well microtiter plates, which contained A. actinomycetemcomitans Y4 biofilms, and incubated at $37{ }^{\circ} \mathrm{C}$ in a $5 \% \mathrm{CO}_{2}$ atmosphere for $1 \mathrm{~h}$. After $1 \mathrm{~h}$ incubation, biofilm assays were performed according to the same method as mentioned above.

\section{Supplementary Information}

The online version contains supplementary material available at https://doi. org/10.1186/s12866-020-02034-9.

\section{Additional file 1: Supplemental Fig. 1. Representative images of $A$. actinomycetemcomitans Y4 (A, D, G), S. mutans UA159 (B, E, H), and S. sanguinis ATCC10556 (C, F, I) biofilms as visualized by confocal microscopy. Non-treatment (0 w/v\%) images $(\mathbf{A}-\mathbf{C})$, rhamnolipids treat- ment $(0.65 \mathrm{w} / \mathrm{v} \%)$ images (D-F), and surfactin treated $(1.04 \mathrm{w} / \mathrm{v} \%)$ images $(\mathbf{G}-\mathbf{H})$ are shown. These bacterial samples were stained by Syto9. Scale bars indicates $10 \mu \mathrm{m}$. Supplemental Fig. 2. Biofilm formation of (A) S. mutans UA159 and (B) S. sanguinis ATCC10556 with sucrose concentra- tions $(0,0.01,0.1$, and $1 \mathrm{~W} / \mathrm{v} \%)$. Error bars indicate standard deviations of at least three experiments.}

\section{Abbreviations}

SEM: Scanning electron microscopy; EPS: Extracellular polymeric substances; DNA: Deoxyribonucleic acid; $\mathrm{BHI}$ : Brain heart infusion; $\mathrm{dH}_{2} \mathrm{O}$ : Distilled water; PBS: Phosphate buffered saline; OD: Optical density

\section{Acknowledgments}

We would like to thank Kaneka Corporation for providing sodium surfactin. We would like to thank Keyence Corporation for their technical support on the use of the confocal microscope. We would like to thank Editage (www editage.com) for their English language editing.

\section{Authors' contributions}

RY performed the experiments and wrote the manuscript. RY, AK, YY, and WA designed the experiments. All other authors have contributed to data collection and interpretation, and critically reviewed the manuscript. All authors read and approved the final manuscript.

\section{Funding}

This work was supported by JSPS KAKENHI (grant numbers 19 K24102 and 20 K18485); and The Yoshida Foundation for the Promotion of Learning and Education. The content is solely the responsibility of the authors and does not necessarily represent the official views of the JSPS in the design and conduct of the study; collection, management, analysis, and interpretation of the data; preparation, review, or approval of the manuscript; and decision to submit the manuscript for publication.

\section{Availability of data and materials}

All data generated or analyzed during this study are included in this published article and its supplementary information files.

Ethics approval and consent to participate Not applicable.

Consent for publication Not applicable.

Competing interests

The authors declare that they have no competing interests. 
Received: 23 April 2020 Accepted: 5 November 2020

Published online: 23 November 2020

\section{References}

1. Donlan RM. Biofilms: microbial life on surfaces. Emerg Infect Dis. 2002;8(9): 881-90.

2. Azeredo J, Azevedo NF, Briandet R, Cerca N, Coenye T, Costa AR, Desvaux M, Di Bonaventura G, Hebraud M, Jaglic Z, et al. Critical review on biofilm methods. Crit Rev Microbiol. 2017:43(3):313-51.

3. Stauch-White K, Srinivasan VN, Camilla Kuo-Dahab W, Park C, Butler CS. The role of inorganic nitrogen in successful formation of granular biofilms for wastewater treatment that support cyanobacteria and bacteria. AMB Express. 2017;7(1):146.

4. Chen T, Liu N, Ren P, Xi X, Yang L, Sun W, Yu B, Ying H, Ouyang P, Liu D, et al. Efficient biofilm-based fermentation strategies for L-threonine production by Escherichia coli. Front Microbiol. 2019;10:1773.

5. Sasaki D, Sasaki K, Tsuge Y, Kondo A. Less biomass and intracellular glutamate in anodic biofilms lead to efficient electricity generation by microbial fuel cells. Biotechnol Biofuels. 2019;12:72.

6. Yamasaki R, Maeda T, Wood TK. Electron carriers increase electricity production in methane microbial fuel cells that reverse methanogenesis. Biotechnol Biofuels. 2018;11:211.

7. Zhu L, Gong T, Wood TL, Yamasaki R, Wood TK. Sigma54 -dependent regulator DVU2956 switches Desulfovibrio vulgaris from biofilm formation to planktonic growth and regulates hydrogen sulfide production. Environ Microbiol. 2019;21(10):3564-76.

8. Bjarnsholt T, Buhlin K, Dufrene YF, Gomelsky M, Moroni A, Ramstedt M, Rumbaugh KP, Schulte T, Sun L, Akerlund B, et al. Biofilm formation - what we can learn from recent developments. J Intern Med. 2018;284(4):332-45.

9. Berger D, Rakhamimova A, Pollack A, Loewy Z. Oral Biofilms: Development, Control, and Analysis. High Throughput. 2018;7(3):24.

10. Fumes AC, da Silva Telles PD, Corona SAM, Borsatto MC. Effect of aPDT on Streptococcus mutans and Candida albicans present in the dental biofilm: systematic review. Photodiagn Photodyn Ther. 2018;21:363-6.

11. Zhu B, Macleod LC, Kitten T, Xu P. Streptococcus sanguinis biofilm formation \& interaction with oral pathogens. Future Microbiol. 2018;13:915-32.

12. Tsai CC, Ho YP, Chou YS, Ho KY, Wu YM, Lin YC. Aggregatibacter (Actinobacillus) actimycetemcomitans leukotoxin and human periodontitis a historic review with emphasis on JP2. Kaohsiung J Med Sci. 2018;34(4): 186-93.

13. Chhibber-Goel J, Singhal V, Bhowmik D, Vivek R, Parakh N, Bhargava B, Sharma A. Linkages between oral commensal bacteria and atherosclerotic plaques in coronary artery disease patients. NPJ Biofilms Microbiomes. 2016;2:7

14. Kampoo K, Teanpaisan R, Ledder RG, McBain AJ. Oral bacterial communities in individuals with type 2 diabetes who live in southern Thailand. Appl Environ Microbiol. 2014;80(2):662-71.

15. Kim JS, Yamasaki R, Song S, Zhang W, Wood TK. Single cell observations show persister cells wake based on ribosome content. Environ Microbiol. 2018;20(6):2085-98.

16. Lewis K. Multidrug tolerance of biofilms and persister cells. Curr Top Microbiol Immunol. 2008;322:107-31.

17. Verderosa AD, Totsika M, Fairfull-Smith KE. Bacterial biofilm eradication agents: a current review. Front Chem. 2019;7:824.

18. Yamasaki R, Song S, Benedik MJ, Wood TK. Persister Cells Resuscitate Using Membrane Sensors that Activate Chemotaxis, Lower cAMP Levels, and Revive Ribosomes. iscience. 2020;23(1):100792.

19. Donlan RM, Costerton JW. Biofilms: survival mechanisms of clinically relevant microorganisms. Clin Microbiol Rev. 2002;15(2):167-93.

20. Kostakioti M, Hadjifrangiskou M, Hultgren SJ. Bacterial biofilms: development, dispersal, and therapeutic strategies in the dawn of the postantibiotic era. Cold Spring Harb Perspect Med. 2013;3(4):a010306.

21. Heriot M, Nottelet B, Garric X, D'Este M, Richards GR, Moriarty FT, Eglin D, Guillaume O. Interaction of gentamicin sulfate with alginate and consequences on the physico-chemical properties of alginate-containing biofilms. Int J Biol Macromol. 2019;121:390-7.

22. Staudt C, Horn H, Hempel DC, Neu TR. Volumetric measurements of bacterial cells and extracellular polymeric substance glycoconjugates in biofilms. Biotechnol Bioeng. 2004;88(5):585-92.

23. Maier RM, Soberon-Chavez G. Pseudomonas aeruginosa rhamnolipids: biosynthesis and potential applications. Appl Microbiol Biotechnol. 2000; 54(5):625-33.
24. Ochsner UA, Fiechter A, Reiser J. Isolation, characterization, and expression in Escherichia coli of the Pseudomonas aeruginosa rhIAB genes encoding a rhamnosyltransferase involved in rhamnolipid biosurfactant synthesis. J Biol Chem. 1994;269(31):19787-95.

25. Stipcevic T, Piljac T, Isseroff RR. Di-rhamnolipid from Pseudomonas aeruginosa displays differential effects on human keratinocyte and fibroblast cultures. J Dermatol Sci. 2005;40(2):141-3.

26. Ahmed S, Rudden M, Smyth TJ, Dooley JSG, Marchant R, Banat IM. Natural quorum sensing inhibitors effectively downregulate gene expression of Pseudomonas aeruginosa virulence factors. Appl Microbiol Biotechnol. 2019; 103(8):3521-35

27. Irie Y. O'Toole G a, yuk MH: Pseudomonas aeruginosa rhamnolipids disperse Bordetella bronchiseptica biofilms. FEMS Microbiol Lett. 2005;250(2):237-43.

28. Wood TL, Gong T, Zhu L, Miller J, Miller DS, Yin B, Wood TK. Rhamnolipids from Pseudomonas aeruginosa disperse the biofilms of sulfate-reducing bacteria. NPJ Biofilms Microbiomes. 2018;4:22.

29. Zeriouh H, de Vicente A, Perez-Garcia A, Romero D. Surfactin triggers biofilm formation of Bacillus subtilis in melon phylloplane and contributes to the biocontrol activity. Environ Microbiol. 2014;16(7):2196-211.

30. Mongkolthanaruk W. Classification of Bacillus beneficial substances related to plants, humans and animals. J Microbiol Biotechnol. 2012;22(12):1597604.

31. Mireles JR 2nd, Toguchi A, Harshey RM. Salmonella enterica serovar typhimurium swarming mutants with altered biofilm-forming abilities: surfactin inhibits biofilm formation. J Bacteriol. 2001;183(20):5848-54.

32. Magalhães $L$, Nitschke $M$. Antimicrobial activity of rhamnolipids against listeria monocytogenes and their synergistic interaction with nisin. Food Control. 2013;29(1):138-42.

33. Nitschke M, Costa SG, Contiero J. Structure and applications of a rhamnolipid surfactant produced in soybean oil waste. Appl Biochem Biotechnol. 2010;160(7):2066-74.

34. Haba E, Pinazo A, Jauregui $O$, Espuny MJ, Infante MR, Manresa A. Physicochemical characterization and antimicrobial properties of rhamnolipids produced by Pseudomonas aeruginosa 47T2 NCBIM 40044. Biotechnol Bioeng. 2003;81(3):316-22

35. de Freitas FJ, Vieira EA, Nitschke M. The antibacterial activity of rhamnolipid biosurfactant is pH dependent. Food Res Int. 2019;116:737-44.

36. Benincasa M, Abalos A, Oliveira I, Manresa A. Chemical structure, surface properties and biological activities of the biosurfactant produced by Pseudomonas aeruginosa LBI from soapstock. Antonie Van Leeuwenhoek. 2004;85(1):1-8.

37. Vatsa P, Sanchez L, Clement C, Baillieul F, Dorey S. Rhamnolipid biosurfactants as new players in animal and plant defense against microbes. Int J Mol Sci. 2010;11(12):5095-108.

38. Aleksic I, Petkovic M, Jovanovic M, Milivojevic D, Vasiljevic B, NikodinovicRunic J, Senerovic L. Anti-biofilm properties of bacterial Di-Rhamnolipids and their semi-synthetic amide derivatives. Front Microbiol. 2017:8:2454.

39. Chebbi A, Elshikh M, Haque F, Ahmed S, Dobbin S, Marchant R, Sayadi S, Chamkha M, Banat IM. Rhamnolipids from Pseudomonas aeruginosa strain W10; as antibiofilm/antibiofouling products for metal protection. J Basic Microbiol. 2017;57(5):364-75.

40. Abdelli F, Jardak M, Elloumi J, Stien D, Cherif S, Mnif S, Aifa S. Antibacterial, anti-adherent and cytotoxic activities of surfactin(s) from a lipolytic strain Bacillus safensis F4. Biodegradation. 2019;30(4):287-300.

41. Korenblum E, de Araujo LV, Guimaraes CR, de Souza LM, Sassaki G, Abreu F, Nitschke M, Lins U, Freire DM, Barreto-Bergter E, et al. Purification and characterization of a surfactin-like molecule produced by Bacillus sp. $\mathrm{H} 2 \mathrm{O}-1$ and its antagonistic effect against sulfate reducing bacteria. BMC Microbiol. 2012;12:252.

42. Loiseau C, Schlusselhuber M, Bigot R, Bertaux J, Berjeaud JM, Verdon J. Surfactin from Bacillus subtilis displays an unexpected anti-Legionella activity. Appl Microbiol Biotechnol. 2015;99(12):5083-93.

43. Nitschke M, Araujo LV, Costa SG, Pires RC, Zeraik AE, Fernandes AC, Freire $\mathrm{DM}$, Contiero J. Surfactin reduces the adhesion of food-borne pathogenic bacteria to solid surfaces. Lett Appl Microbiol. 2009:49(2):241-7.

44. do Valle Gomes MZ, Nitschke M. Evaluation of rhamnolipid and surfactin to reduce the adhesion and remove biofilms of individual and mixed cultures of food pathogenic bacteria. Food Control. 2012;25(2):441-7.

45. Zhao F, Zhou JD, Ma F, Shi RJ, Han SQ, Zhang J, Zhang Y. Simultaneous inhibition of sulfate-reducing bacteria, removal of $\mathrm{H} 2 \mathrm{~S}$ and production of rhamnolipid by recombinant Pseudomonas stutzeri Rhl: applications for microbial enhanced oil recovery. Bioresour Technol. 2016;207:24-30. 
46. Juhas M, Eberl L, Tummler B. Quorum sensing: the power of cooperation in the world of Pseudomonas. Environ Microbiol. 2005;7(4):459-71.

47. Solano C, Echeverz M, Lasa I. Biofilm dispersion and quorum sensing. Curr Opin Microbiol. 2014:18:96-104

48. Bachtiar EW, Bachtiar BM, Jarosz LM, Amir LR, Sunarto H, Ganin H, Meijler MM, Krom BP. Al-2 of Aggregatibacter actinomycetemcomitans inhibits Candida albicans biofilm formation. Front Cell Infect Microbiol. 2014;4:94.

49. Shao H, Lamont RJ, Demuth DR. Autoinducer 2 is required for biofilm growth of Aggregatibacter (Actinobacillus) actinomycetemcomitans. Infect Immun. 2007;75(9):4211-8.

50. Plancak D, Music L, Puhar I. Quorum sensing of periodontal pathogens. Acta Stomatol Croat. 2015;49(3):234-41.

51. Bescos R, Ashworth A, Cutler C, Brookes ZL, Belfield L, Rodiles A, CasasAgustench P, Farnham G, Liddle L, Burleigh M, et al. Effects of Chlorhexidine mouthwash on the oral microbiome. Sci Rep. 2020;10(1):5254

52. Hoang T, Jorgensen M, Keim R, Pattison A, Slots J. Povidone-iodine as a periodontal pocket disinfectant. J Periodontal Res. 2003;38(3):311-7.

53. Rashed HT. Evaluation of the effect of hydrogen peroxide as a mouthwash in comparison with chlorhexidine in chronic periodontitis patients: a clinical study. J Int Soc Prev Community Dent. 2016;6(3):206.

54. Yates R, Moran J, Addy M, Mullan PJ, Wade WG, Newcombe R. The comparative effect of acidified sodium chlorite and chlorhexidine mouthrinses on plaque regrowth and salivary bacterial counts. I Clin Periodontol. 1997:24(9 Pt 1):603-9.

55. Herrera D, Escudero N, Pérez L, Otheo M, Cañete-Sánchez E, Pérez T, Alonso B, Serrano J, Palma JC, Sanz M. Clinical and microbiological effects of the use of a cetylpyridinium chloride dentifrice and mouth rinse in orthodontic patients: a 3-month randomized clinical trial. Eur J Orthod. 2018;40(5):46574.

56. Preshaw P. Mouthwash use and risk of diabetes. Br Dent J. 2018;225(10): 923-6.

57. Takenaka S, Ohsumi T, Noiri Y. Evidence-based strategy for dental biofilms: current evidence of mouthwashes on dental biofilm and gingivitis. Jpn Dent Sci Rev. 2019;55(1):33-40.

58. Pemberton MN. Allergy to Chlorhexidine. Dent Update. 2016;43(3):272-4.

59. Rees TD, Orth CF. Oral ulcerations with use of hydrogen peroxide. J Periodontol. 1986;57(11):689-92.

60. Pontefract H, Hughes J, Kemp K, Yates R, Newcombe R, Addy M. The erosive effects of some mouthrinses on enamel: a study in situ. J Clin Periodontol. 2001;28(4):319-24.

61. Kanno S, Hirano S, Kato H, Fukuta M, Mukai T, Aoki Y. Benzalkonium chloride and cetylpyridinium chloride induce apoptosis in human lung epithelial cells and alter surface activity of pulmonary surfactant monolayers. Chem Biol Interact. 2020;317:108962

62. Sekhon Randhawa KK, Rahman PK. Rhamnolipid biosurfactants-past, present, and future scenario of global market. Front Microbiol. 2014:5:454.

63. Taira T, Yanagisawa S, Nagano T, Tsuji T, Endo A, Imura T. pH-induced conformational change of natural cyclic lipopeptide surfactin and the effect on protease activity. Colloids Surf B Biointerfaces. 2017;156:382-7.

64. Norskov-Lauritsen N, Kilian M. Reclassification of Actinobacillus actinomycetemcomitans, Haemophilus aphrophilus, Haemophilus paraphrophilus and Haemophilus segnis as Aggregatibacter actinomycetemcomitans gen. Nov., comb. nov., Aggregatibacter aphrophilus comb. nov. and Aggregatibacter segnis comb. nov., and emended description of Aggregatibacter aphrophilus to include $V$ factordependent and $\mathrm{V}$ factor-independent isolates. Int J Syst Evol Microbiol. 2006;56(Pt 9):2135-46.

65. Ajdic D, McShan WM, McLaughlin RE, Savic G, Chang J, Carson MB, Primeaux C, Tian R, Kenton S, Jia H, et al. Genome sequence of Streptococcus mutans UA159, a cariogenic dental pathogen. Proc Natl Acad Sci U S A. 2002:99(22):14434-9.

\section{Publisher's Note}

Springer Nature remains neutral with regard to jurisdictional claims in published maps and institutional affiliations. 